\title{
Study on mechanical properties and microstructure of DP590 steel with different annealing process
}

\author{
Libo Pan ${ }^{1, *}$, Chengjiang Lin ${ }^{2}$, Wenqiang Zhou ${ }^{2}$ and zhijiang Zuo ${ }^{1}$ \\ ${ }^{1}$ Insititute of Intelligent Manufacturing, Jianghan University, 430056, Wuhan, China \\ ${ }^{2}$ Baosteel Central Research Institute, 430056, Wuhan, China
}

\begin{abstract}
Annealing process is critical to mechanical properties and microstructure of DP steel. For DP steel with strength grade of $590 \mathrm{MPa}$, experiments with different combinations of intercritical annealing temperature and over-aging temperature were carried out during annealing. The tensile tests of the final products and nanohardness tests of different phases were made, and the microstructures were analyzed. The results indicated that higher intercritical annealing temperature was favorable to higher volume fraction of martensite and lower nanohardness of martensite with lower $\mathrm{C}$ density. The ultimate tensile strength increased monotonously with the volume fraction of martensite increasing. Higher over aging temperature would make martensite islands be partially resolved and carbides precipitate, which made lower volume fraction of martensite, and resulted in lower nanohardness of martensite. The revealed rules could provide important guide to control material properties of DP steel by manipulating annealing process.
\end{abstract}

\section{Introduction}

Dual phase steels had been widely used in automotive industry for light-weighting and safety. The high strength-to-weight ratio, low yield-to-ultimate strength ratio combined with a high initial work hardening rate and good formability of DP steels make them particularly suitable for structure and safety part forming in car body[1-3]. Generally, this type of steel is mainly composed of ferrite and martensite, which obtained from annealing process during manufacturing. Many scholars carried out researches on mechanical properties and microstructure evolution on different strength grades of DP steels[4-7]. A. K. Jena[8] studied DP steel prepared from different intercritical annealing temperature and set up a nonlinear relationship between tensile strength and volume fraction of martensite. S. Pandre[9] investigated tensile deformation behaviour and material properties of DP steel at different temperatures and strain rates. R. K. Singh[10] found that rapid cooling temperature had strong effect on tensile strength. Basicallly the mechanical properties of DP steel are fundamentally determined by strength and volume fraction of these two phases. However, the strength for ferrite and martensite is not easy to be evaluated. And some cementite with bainitic morphology might occur in microstructure through employing different annealing parameters, which may also have influence to the final mechanical properties. In this study, nano-hardness of different phases were tested to evaluate phase strength at the micro-scale by utilizing an advanced nano-indentation technique, and microstructure were analyzed for DP590 samples produced from different annealing parameters, which explained the influencing mechanism of annealing process to macro-and micro properties of DP steel.

\section{Material and experimental procedure}

The DP590 steel investigated were manufactured in production line with the main chemical composition listed in Table 1. This type of DP material contains high $\mathrm{C}$ and $\mathrm{Al}$ with addition of Mo. During hot rolling, the final rolling temperature is about $860^{\circ} \mathrm{C}$ and the coiling temperature is about $580^{\circ} \mathrm{C}$, then the sheets are cold rolled to $1.5 \mathrm{~mm}$ with a thickness reduction rate of nearly $60 \%$. In continuous annealing process, the intercritical annealing temperature and over-aging temperature are critical to the properties of DP steel. Three different combinations of annealing parameters as shown in Table 2 were employed during annealing while other process parameters were kept the same, which led to three different products steel A, steel B and steel C. It can be seen that steel A and steel B were produced with different intercritical annealing temperature with similar over-aging temperature of about $270^{\circ} \mathrm{C}$, while steel $\mathrm{B}$ and steel $\mathrm{C}$ were produced with different over-aging temperature with similar intercritical annealing temperature of about $800^{\circ} \mathrm{C}$.

Table 1. The main chemical composition.

\begin{tabular}{|c|c|c|c|c|c|c|c|}
\hline \multicolumn{7}{|c|}{ Chemical Composition [wt\%] } \\
\hline $\mathrm{C}$ & $\mathrm{Si}$ & $\mathrm{Mn}$ & $\mathrm{P}$ & $\mathrm{S}$ & Alt & Mo & $\mathrm{N}$ \\
\hline 0.097 & 0.12 & 1.38 & 0.010 & 0.003 & 0.92 & 0.14 & 0.003 \\
& & & & & & & \\
\hline
\end{tabular}

\footnotetext{
* Corresponding author: pan97181@126.com
} 
Table 2. The different combinations of annealing parameters.

\begin{tabular}{|c|c|c|}
\hline $\begin{array}{c}\text { Material } \\
\text { type }\end{array}$ & $\begin{array}{c}\text { Intercritical annealing } \\
\text { temperature }\left({ }^{\circ} \mathrm{C}\right)\end{array}$ & $\begin{array}{c}\text { Over-aging } \\
\text { temperature }\left({ }^{\circ} \mathrm{C}\right)\end{array}$ \\
\hline Steel A & $820 \pm 10$ & $270 \pm 10$ \\
\hline Steel B & $800 \pm 10$ & $270 \pm 10$ \\
\hline Steel C & $800 \pm 10$ & $300 \pm 10$ \\
\hline
\end{tabular}

Samples from three different steels were tested and analyzed. The tensile test was carried out at room temperature on a Zwick universal tensile testing machine by using BS EN10002-1 specimens. The specimens were tested along transversal direction with the gauge length of $80 \mathrm{~mm}$. In order to clarify individual properties of ferrite and martensite in dual-phase steel, the nanoindentation hardness tests were conducted by employing an ultra micro-indentation system (UMIS) as shown in Fig.1 to check the nano-hardness of ferrite and martensite. Before nanohardness test, the samples were polished with diamond paste and then colloidal silica. The colloidal silica would slightly etch the sample surface and therefore remove the deformation layer. The microstructures of steel samples were observed through optical microscopy (OM) and scanning electron microscopy (SEM).

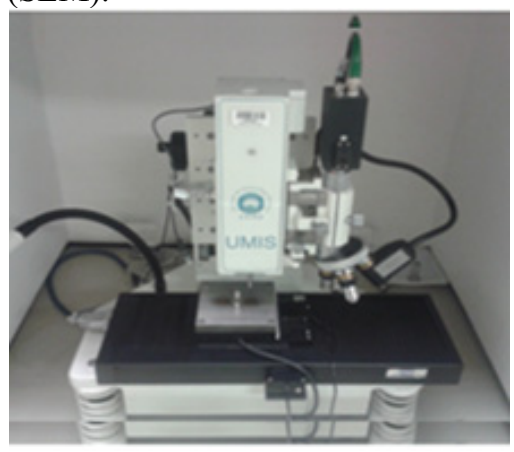

Fig. 1. UMIS nano-indentation instrument

\section{Result and analysis}

\subsection{Mechanical properties}

The mechanical properties of steel A, steel B and steel C are listed in Table 3 . Under the condition of similar overaging temperature, steel $\mathrm{A}$ has much higher ultimate tensile strength (UTS) and lower total elongation (E) than steel B with higher intercritical annealing temperature. Steel C shows lower UTS and higher total elongation than steel $\mathrm{B}$ with higher over-aging temperature. The yield strengths (YS) for three steels are at the same level. Steel $\mathrm{C}$ exhibits the highest $\mathrm{n}$ value.

Table 3. Mechanical properties for materials.

\begin{tabular}{|c|c|c|c|c|}
\hline $\begin{array}{c}\text { Material } \\
\text { type }\end{array}$ & $\begin{array}{c}\text { YS } \\
\mathrm{MPa}\end{array}$ & $\begin{array}{c}\text { UTS } \\
\mathrm{MPa}\end{array}$ & $\begin{array}{c}\mathrm{TE} \\
\mathrm{A}_{80 \mathrm{~mm} \%}\end{array}$ & $\mathrm{n}_{90}$ \\
\hline Steel A & 368 & 687 & 19 & 0.13 \\
\hline Steel B & 355 & 635 & 22 & 0.16 \\
\hline Steel C & 365 & 584 & 26 & 0.17 \\
\hline
\end{tabular}

It seems that both higher intercritical annealing temperature and lower over-aging temperature are favorable to higher UTS and would degrade total elongation of DP steel.

\subsection{Nanohardness test}

Fig. 2 shows an example for shape and diameter of nanoindentation located in martensite. Generally, green circle with bigger nano-indentation diameter signifies higher nanohardness. It could be know that the nanohardness of martensite is much higer than that of ferrite. Fig. 3 shows an example for different shape of nano-indentation located in different ferrite, which indicates that the nanohardness of different ferrite is different, normally nanohardness of ferrite near to martensite or grain boundary are both relatively higher than the ones located in middle of ferrite.

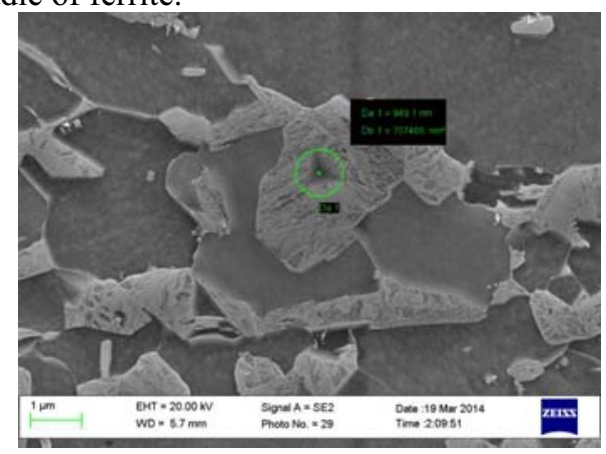

Fig. 2. Nanoindentation shape and diameter example for martensite.

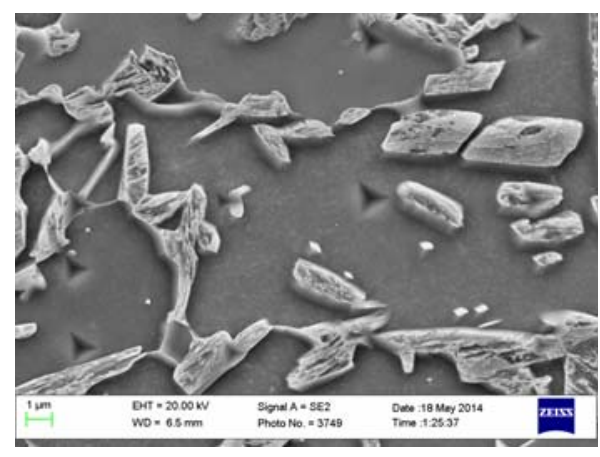

Fig. 3. Nanoindentation shape example for different ferrites.

The nanohardness distribution is statistically shown in Fig.4. From the result, it indicates that steel A and steel B has similar nanoharndess distribution in ferrite and also most of martensite region, but the nanohardness frequency of steel B appears a peak at the value of $8.8 \mathrm{Gpa}$, which is probably caused by nanohardness increasement in some martensite region because of carbide precipitation. And it seems to be much higher frequency for steel $\mathrm{B}$ in the high nanohardness area above $8 \mathrm{GPa}$. For steel $\mathrm{C}$, the highest nanohardness is lower than that of the other two materials and there is much lower frequency in the nanohardness area above $7 \mathrm{GPa}$, which means the nanohardness of martensite in steel $\mathrm{C}$ should be lower than that in steel $\mathrm{A}$ and steel $\mathrm{B}$. It could be seen that the ferrite peak for steel $C$ is a little left shift, therefore, its' ferrite nanohardness might be lower. 


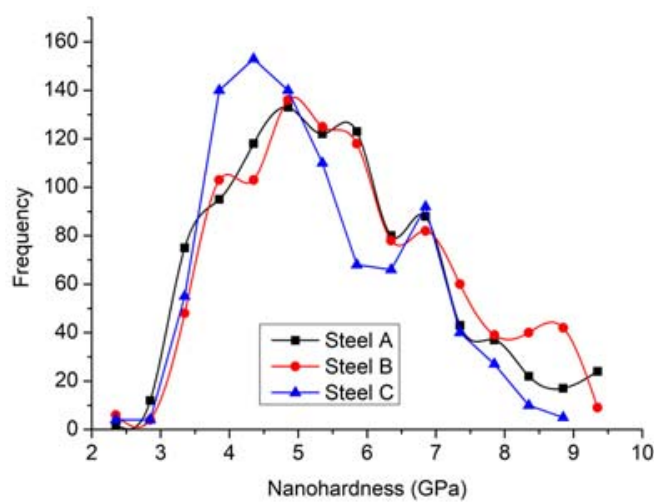

Fig. 4. Nanohardness distribution for three DP590 steel.

The mean nanohardness for ferrite and martensite of three samples are shown in Table 4. The result indicates that the mean ferrite and martensite nanohardness of steel B are both the highest. And steel $\mathrm{C}$ has the lowest mean ferrite and martensite nanohardness, which is in agreement with the result from nanohardness distribution.

Table 4. The mean nanohardness for ferrite and martensite

\begin{tabular}{|c|c|c|}
\hline \multirow{2}{*}{$\begin{array}{c}\text { Material } \\
\text { type }\end{array}$} & \multicolumn{2}{|c|}{ Mean Nanohardness (GPa) } \\
\cline { 2 - 3 } & Ferrite & Martensite \\
\hline Steel A & $4.75 \pm 0.85$ & $7.35 \pm 0.80$ \\
\hline Steel B & $4.85 \pm 0.80$ & $7.53 \pm 0.80$ \\
\hline Steel C & $4.45 \pm 0.65$ & $7.15 \pm 0.95$ \\
\hline
\end{tabular}

\subsection{Microstructure quantitative measurement}

The microstructure for steel A is shown in Fig.5. The dark area represents martensite while the bright area represents ferrite. Based on the images of microstructure, the volume fraction of martensite were analyzed through quantitative measurement as shown in Fig.6. The volume fraction of martensite for three materials are $14.4 \%$, $12.7 \%$ and $10.2 \%$, respectively. Generally for DP steel, the volume fraction of martensite have strong effect on ultimate tensile strength. From the result above, the relationship between UTS and volume fraction of martensite for three materials could be plotted in Fig.7, it could be known that the ultimate tensile strength increases monotonously with the volume fraction of martensite increasing.

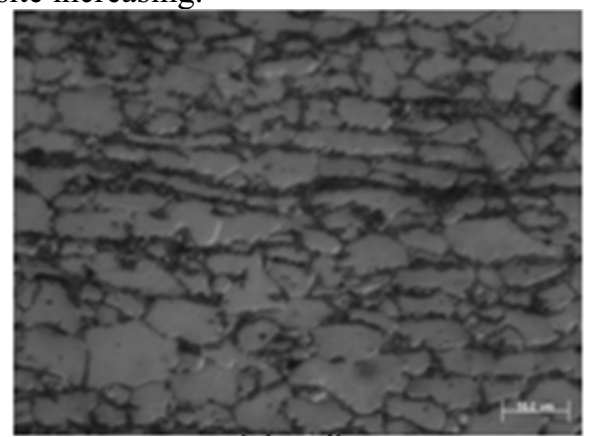

Fig. 5. Optical microstructure for steel A.
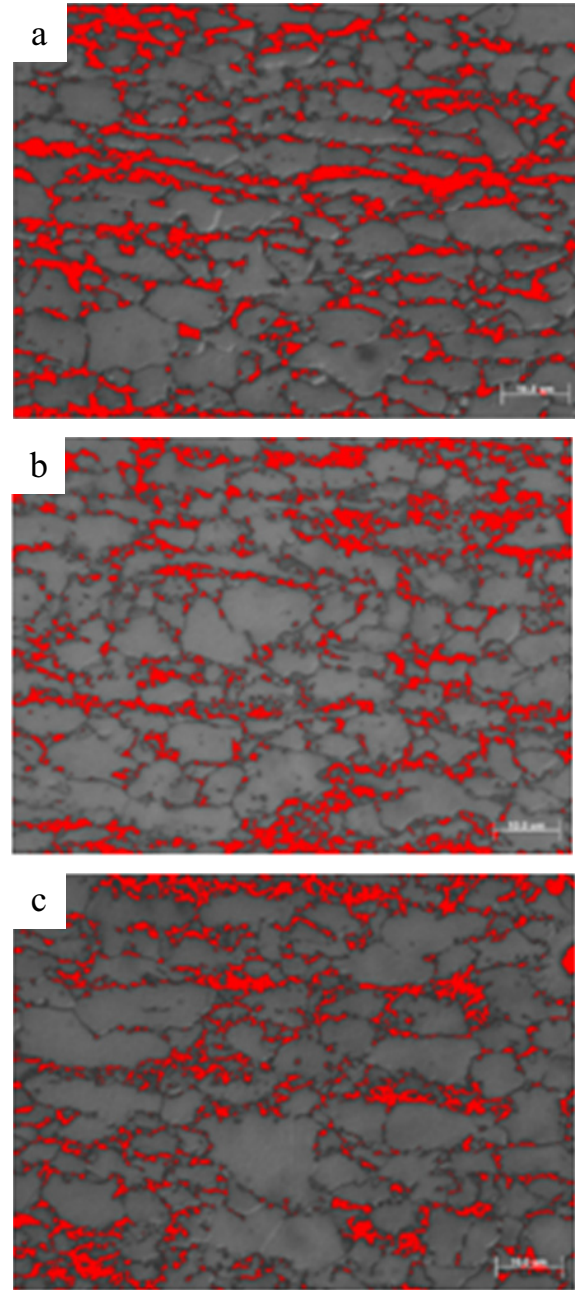

Fig. 6. Quantitative measurement images for volume fraction of martensite. (a)Steel A, (b)Steel B, (c)Steel C.

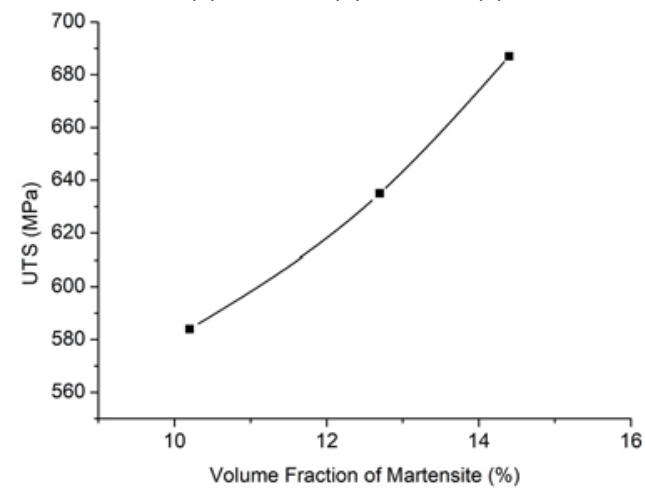

Fig. 7. Effect of volume fraction of martensite on ultimate tensile strength.

For steel A and steel $\mathrm{B}$, the intercritical annealing temperature are about $820^{\circ} \mathrm{C}$ and $800^{\circ} \mathrm{C}$, respectively. Generally, higher intercritical annealing temperature would result in more austenite formation during recrystallization and then more martensite after austenite-martensite transformation during cooling, which explains why steel A has higher volume fraction of martensite than steel B. On the other hand, the strength of martensite is highly dependent on $\mathrm{C}$ content. High $\mathrm{C}$ density in martensite may lead to high martensite strength. Because of the higher volume fraction of martensite, the $\mathrm{C}$ density in steel A would be lower, 
which results in lower mean nanohardnees of martensite in steel A compared with steel B.

The SEM photos of Steel $\mathrm{C}$ are shown in Fig.8. Fig.8(b) presents the detailed microstructure morphology in some specific area. A lot of carbides could be observed. As stated above, during manufacturing the over-aging temperature for steel $\mathrm{B}$ and steel $\mathrm{C}$ are about $270^{\circ} \mathrm{C}$ and $300^{\circ} \mathrm{C}$, respectively, with other process parameters the same. Basically, higher over-aging temperature during annealing was employed for steel $\mathrm{C}$, and it would accelerate the decomposition of martensite, or result in the formation of bainite. Therefore, a lot of martensite islands are partially resolved and some carbide precipitates among martensite islands in steel $\mathrm{C}$, which explained why the volume fraction of martensite for steel $\mathrm{C}$ is lower than that for steel $\mathrm{B}$, and also made the nanohardness of martensite in steel $\mathrm{C}$ lower. Consequently the ultimate tensile strength of steel C is lower than that of steel B.
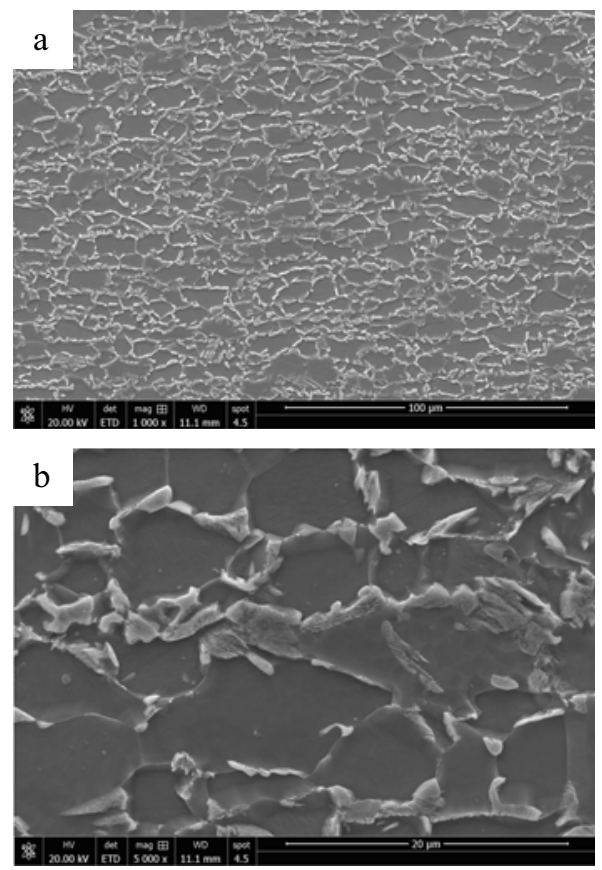

Fig. 8. SEM photoes of steel C. (a)Steel C, (b)Detailed area with magnification.

\section{Conclusion}

The experiments with different annealing process especially different intercritical annealing temperature and over-aging temperature were carried out on DP590 steel. The tensile test, nanohardness test and microstructure observation were performed. The results allow to draw the following major conclusions.

(1) Intercritical annealing temperature is critical to mechanical properties of DP steel. High intercritical annealing temperature is favorable to high volume fraction of martensite and high ultimate tensile strength. Because of the higher volume fraction of martensite, the $\mathrm{C}$ density in martensite would be lower, which results in lower mean nanohardnees of martensite.

(2) The ultimate tensile strength increases monotonously with the volume fraction of martensite increasing.

(3) Higher over-aging temperature could result in lower ultimate tensile strength. At higher over aging temperature, martensite islands would be partially resolved and some carbide precipitates among martensite islands, which makes lower volume fraction of martensite, and results in lower nanohardness of martensite.

\section{References}

1. F. Ozturk, S. Toros, S. Kilic, J. Iron Steel Res. Int.,16, 41(2009)

2. B. L. Ma, Z. G. Liu, Z. Jiang, X. D. Wu, K. S. Diao, M. Wan, Mater. Des., 96, 401(2016)

3. A. Chakraborty, M. Adhikary, T. Venugopalan, V. Singh, T. Nanda, B. R. Kumar, Mater. Sci. Eng., A 676, 463(2016)

4. K. H. Chung, W. Lee, J. H. Kim, C. Kim, S. H. Park, D. Kwone, K. Chung, Int. J. Solids Struct., 46, 344(2009)

5. B. Bayramin, C. Simsir, M. Efe, Mater. Sci. Eng., A 704, 164 (2017)

6. H. Y. Yu, J. Y. Shen, Mater. Des., 63, 412(2014)

7. J. Liao, J. A. Sousa, A. B. Lopes, X. Xue, F. Barlat, A. B. Pereira, Int. J. Plast., 93, 269 (2017)

8. A. K. Jena, M. C. Chaturvedi, Mater. Sci. Eng., A 100, 1(1998)

9. S. Pandre, P. Takalkar, N. Kotkunde, S. K. Singh, A. U. Haq, Mater. Today: Proc., 18, 2603(2019)

10. R. K. Singh, M. Chandrawanshi, R. Sudharshan, D. Mishra, A. Chandra, Mater. Today: Proc., 5, 7303(2018) 